\title{
O DISCURSO PUBLICITÁRIO NO ESPETÁCULO DA MÍDIA: EM CENA O CORPO FEMININO
}

Tânia Maria Augusto Pereira é Doutora em Linguística (PROLING/UFPB). Professora da Universidade Estadual da Paraíba e atua em pesquisas na área de Análise do Discurso, na perspectiva francesa.

E-mail: taniauepb@yahoo.com.br

\section{Resumo}

Este artigo apresenta uma reflexão sobre como os agenciamentos do discurso publicitário na mídia configuram a produção biopolítica do corpo saudável, magro, jovem e, portanto, belo. Este discurso é legitimado e mantido pela mídia através das técnicas usadas para disciplinar os corpos.

\begin{abstract}
This article presents reflections on the manner in which the assemblages of advertising discourse in media coverage configure the biopolitical construction of the healthy, slim, young and consequently, beautiful, body. This discourse is legitimized and maintained by the media through the techniques used to propagate discipline with regard to the body.
\end{abstract}

\section{1) Comentários iniciais}

Os discursos midiáticos contemporâneos enfatizam uma identificação associada a imagens modelares que produzem uma "estética de si" como um estilo de vida a ser adotado pelos sujeitos (FOUCAULT, 2007). Interpretar o corpo perfeito apresentado nos anúncios publicitários faz circular discursos que se interpenetram, se completam e se distanciam, que são evidenciados e apagados, recuperados e esquecidos. Considerando que os anúncios publicitários veiculados na mídia contemporânea são produtores de discursos que afetam diretamente a construção dos sujeitos sociais, objetivamos discutir a exposição publicitária que propaga a imagem corporal e as estratégias utilizadas para convencer as mulheres a moldarem seus corpos a partir de um padrão de beleza.

Inseridos em uma sociedade de controle, na qual podemos observar o preceito foucaultiano de controle-estimulação: "Fique nu... mas seja magro, bonito e bronzeado!" (FOUCAULT, 2008a, p. 147), conduziremos nosso estudo dentro do viés da estetização do sujeito moderno que está subordinado a um padrão estético, a uma discursividade que considera a mídia como uma grande produtora de sentidos sobre o corpo.

\section{2) O discurso sobre o corpo na contemporaneidade}

Assim como se modificam historicamente as condições concretas de produção social, política e econômica dos corpos se mudam de forma igualmente histórica as condições da sua estetização. É redundante afirmar que as concepções e padrões estéticos se transformam ao longo da história. Basta notar que o século XX foi muito rico em diversidade estética, fazendo, literalmente, desfilar na passarela da mídia sucessivas modas, variados padrões corporais, e também tecnologias, muitas delas médicas, de produção e modelagem dos corpos, segundo uma estética corporal que se 
modifica historicamente. Não é o corpo que muda ao longo do tempo, mas sim o nosso olhar/discurso sobre ele.

Os mecanismos de poder estão presentes em todos os aspectos sociais, principalmente no que se refere ao corpo. Para Foucault (2008a, p. 80), o controle da sociedade sobre os indivíduos começou no corpo, com o corpo. "Foi no biológico, no somático, no corporal que, antes de tudo, investiu a sociedade capitalista. O corpo é uma realidade bio-política".

Segundo Gregolin (2007b, p. 19-20), o biopoder "materializa-se no governo de si: o sujeito deve autocontrolar-se, modelar-se a partir das representações que the indicam como deve (e como não deve) ser o seu corpo". Plastificado pelas intervenções possibilitadas pelos avanços da tecnologia e da ciência, o corpo é cada vez mais jovem, busca continuamente a longevidade, é construído e reconstruído nas imagens da mídia, tornando-se utopia para cada corpo real.

A ditadura da beleza corporal não é exclusividade do século XXI, pois o corpo sempre foi instrumento de culto nos diversos momentos da história, embora em cada período os processos disciplinadores tenham sido diferentes. Segundo Foucault (2009, p. 133), é assim que nasce a arte do corpo humano, que busca aperfeiçoar as habilidades do físico e formar relações que o tornem mais obediente e útil.

A sociedade busca adequar os corpos aos padrões estéticos estabelecidos, não mais pela coerção e sim pela sedução, revelando uma verdadeira ditadura da beleza, da magreza e da juventude. O controle sobre o corpo exercido pela sociedade vai "ao encontro" dos interesses do mercado (moda, mídia, publicidade etc.) e da indústria da metamorfose (cirurgias, tratamentos, equipamentos e medicamentos com fins estéticos) criando novos sentidos e necessidades para os "consumidores".

A construção de sentidos e significados atribuídos ao corpo, na sociedade contemporânea, não se assemelha aos mesmos sentidos apresentados em épocas passadas. A beleza é um atributo necessário, quase obrigatório, na atualidade. $\mathrm{O}$ corpo se tornou o lugar da identidade pessoal. Segundo Hall (2006, p. 7), vivenciamos uma "crise de identidade" do sujeito, devido a uma mudança estrutural nas sociedades modernas, que fragmentou as paisagens culturais de classe, sexualidade, etnia, raça e nacionalidade, que nos forneciam "sólidas localizações" como indivíduos sociais. Nossas identidades pessoais estão mudando, a ideia de nós próprios como sujeitos integrados está abalada e isso acarreta um deslocamento do sujeito de seu lugar no mundo social, o que significa uma perda do "sentido de si". Prometendo realizar sonhos, a publicidade busca fórmulas mágicas para que o consumidor se veja refletido nas imagens veiculadas, estimulando sua "identificação" com o produto anunciado.

Nas últimas décadas do século $\mathrm{XX}$, observamos o avanço surpreendente do espaço das imagens sobre o espaço das palavras. As imagens falam por si mesmas e ocupam cada vez mais o espaço midiático. Hoje, nossa vida cotidiana está permeada de mensagens visuais. Elas podem ser lidas e interpretadas, social e historicamente. Vivemos na era da semiótica, na qual a imagem é vista como informação, como texto e como discurso. Existe uma propagação invasiva de imagens que ocupam cada vez mais espaço em nosso cotidiano, ilustrando textos e se propondo como textos. 
O corpo se tornou uma valiosíssima imagem para ser exibida na sociedade do espetáculo (DEBORD, 1997), em que a nova superficialidade, a crise da historicidade e a produção de imagens e simulacros traduzem-se na padronização, na virtualização e na comercialização do corpo como objeto rentável. Neste cenário, o sujeito tem uma ilusão de liberdade, de que pode intervir no próprio corpo, reinventando-o a partir de escolhas individuais, sem se dar conta de que suas escolhas são, geralmente, impostas pela mídia, espaço privilegiado do discurso sobre o cuidado de $\mathrm{si}^{1}$, que estabelece o corpo como produção simbólica.

A noção de espetáculo, como desenvolvida por Guy Debord, permite-nos refletir sobre a natureza das representações corporais na contemporaneidade. Para o autor, "toda a vida das sociedades nas quais reinam as modernas condições de produção se apresenta como uma imensa acumulação de espetáculos. Tudo o que era vivido diretamente tornou-se uma representação" (DEBORD, 1997, p. 167).

A expansão dos meios de comunicação audiovisuais situa simbolicamente uma mensagem de felicidade individual na imagem do corpo ou de determinados modelos de corpo. Com a propagação da cultura de consumo, o corpo passou a ser consumido como um objeto rentável. Esse consumo está relacionado não apenas à compra de mercadorias, mas também ao consumo de imagens e valores, que produzem comportamentos e novos modos de pensar, sentir e agir.

A valorização do corpo como imagem de valor simbólico é um dos elementos mais importantes na constituição da identidade do sujeito da pós-modernidade. Segundo Santaella (2004, p. 29), o sujeito não é constante, ele é uma variável em contínua modificação. A autora aponta algumas razões para isso, entre elas: "a fragmentação do sujeito, a espetacularização do mundo na desmesura da proliferação de imagens, sobretudo as imagens do corpo [...]".

A autora também aponta como responsável pelas transformações das noções de corpo a "idealização do corpo como projeto", que implica no estabelecimento de um plano através do qual o sujeito poderia alcançar uma série de objetivos pessoais, quase sempre relacionados com a saúde ou com a aparência. Na pós-modernidade parece haver uma incerteza sobre o conceito de corpo. As múltiplas possibilidades que o corpo pode apresentar contrastam com a incerteza sobre o que fazer com essas possibilidades. Não sabemos como intervir nos nossos corpos sem que se apresentem dilemas morais. Parece haver uma insatisfação constante dos sujeitos com suas formas corporais. $\mathrm{O}$ corpo é encarado como um projeto e como tal, ele está passível a sofrer alterações, a tomar rumos inesperados.

Vivemos uma época em que o corpo e seu significado sócio-cultural tomaram dimensões inusitadas. A insistente veiculação na mídia de imagens de corpos esbeltos ou musculosos, unidas a enunciados sobre felicidade, êxito e auto-estima, fixou no inconsciente coletivo a ideia de que um corpo perfeito é sinônimo de vida perfeita.

1 Adentrar na noção do cuidado de si implica lidar com práticas de subjetivação. Foucault (2007) privilegiou o modo como o poder penetra nos corpos e produz subjetividades. Por esse motivo, suas investigações se voltaram para as tecnologias de si ou do "eu", relacionadas ao cuidado de si. 
O sociólogo polonês Zygmunt Bauman (2001) considera metaforicamente que esta época é líquida, é escorregadia, é fluida, não tem a firmeza e a estabilidade dos sólidos. O durável é substituído pelo transitório, nas mais diversas esferas, inclusive na identidade individual. Com base no autor, podemos conceituar identidade na contemporaneidade como uma colagem de elementos realizada pelo indivíduo para formar imagens agradáveis de si mesmo, imagens estas que não são definitivas, são constantemente reformuladas.

\section{3) Considerações sobre o texto publicitário}

Na concepção de Carvalho (2000), no texto publicitário, o elemento verbal que representa a ordem ou convite constitui um imperativo revestido de roupagens que camuflam as intenções do texto. Para persuadir e seduzir, o anúncio publicitário se utiliza de estratégias linguísticas, de modo a estabelecer uma personalidade para o produto, dotando-o de atributos e promovendo-o pela celebração do nome.

O anúncio publicitário produz uma profusão de imagens e símbolos que, conectados à linguagem verbal, criam e exibem um mundo perfeito e ideal provocando no consumidor uma sensação maior de desejo e, consequentemente, uma aceitação sem qualquer tipo de questionamento, que só reafirma o poder de persuasão dos meios midiáticos.

De acordo com Vestergaard \& Schroder (2000, p. 7), o objetivo final de toda propaganda é vender o produto, mas, para ser tecnicamente eficaz, o publicitário deve estimular primeiramente o desejo de compra e despertar a atenção do consumidor através de mensagens sedutoras. A propaganda procura estimular o desejo de consumo e criar a convicção sobre a qualidade do produto, através de vantagens como o preço e a funcionalidade.

Para Carvalho (2000, p. 17), “o discurso publicitário é um dos instrumentos de controle social" e realiza esta função substituindo termos que indicam autoridade e poder pela linguagem da sedução. Na visão da pesquisadora, a publicidade induz a uma visão dinâmica do social, privilegiando as ideias mais atuais, os fatos emergenciais, as inovações tecnológicas, as novidades de última hora.

O texto publicitário, qualquer que seja a mensagem implícita, é o testemunho de uma sociedade de consumo e conduz a uma representação da cultura a que pertence, permitindo estabelecer uma relação pessoal com a realidade particular. Sua mensagem primeira e explícita é o estímulo ao consumo de um produto, mas ele põe em destaque determinado aspecto de uma cultura, como um projetor poderoso, sem deixar de criar em torno de si algumas zonas de sombra (CARVALHO, 2000, p.106).

A publicidade, muitas vezes, sustenta seu discurso nas conotações culturais e linguísticas, como também, naquelas que vinculam estereótipos, mais facilmente codificáveis e compreensíveis. O anúncio publicitário utiliza as palavras com a carga 
cultural que possui na comunidade em que é veiculado, tentando não contrariar o estabelecido, para que possa ser entendido e aceito (CARVALHO, 2000, p. 102).

Nesse contexto, Vestergaard \& Schroder (2000, p. 174), ao tratarem dos dois sistemas referenciais mais comuns utilizados na publicidade, natureza e história, confirmam que o anúncio exemplifica a forma básica de exploração da história em mensagens comerciais. Ou seja, uma vez que o presente é vivenciado como insuficiente, os anúncios projetam imagens de uma história mítica e imprecisa para conferir autoridade cultural aos produtos apresentados. O sentido de "natural" se tornou o grau de aproximação da natureza que uma cultura histórica define como desejável.

Quando a propaganda o emprega, o "natural", por consequência, torna-se um mecanismo que permite à cultura apropriar-se das qualidades positivas associadas com a natureza e fazer essas qualidades, desprovidas da respectiva substância, aderirem aos produtos de fabricação industrial (VESTERGAARD \& SCHRODER, 2000, p.176).

Assim, o anúncio publicitário é cercado de recursos (repetições de sons, valorização de certas estruturas morfossintáticas etc.) que pretendem, entre outros objetivos, provocar o interesse do consumidor; estimular o desejo de compra e chamar a atenção do leitor, através de mensagens de consumo. Para isso, produz uma profusão de imagens e símbolos que, conectados a linguagem verbal, criam e exibem um mundo perfeito e ideal, provocando no leitor/ouvinte uma sensação maior de desejo e, consequentemente, uma aceitação sem qualquer tipo de questionamento, que reafirma o poder de persuasão.

Na contemporaneidade, acontece uma busca desenfreada pelo modelo corporal que é apresentado na mídia e os sujeitos buscam mudanças desde as mais simples até as formas radicais de transformação corporal para alcançar a beleza. O corpo é um gerador de linguagens, visto como mercadoria, objeto de consumo, alvo de investimentos. $\mathrm{O}$ discurso publicitário concentra no corpo investimentos simbólicos e unifica-o em um padrão único dentro de um campo de controle simbólico que se sobrepõe através da cultura das aparências.

\section{4) Um olhar sobre o corpo das mulheres no discurso publicitário}

O texto publicitário, como tantos outros textos que tratam da imagem feminina, mantem um status quo vigente, refletido na atual situação da mulher. Contribui para a delimitação das diferenças e das ações ao imprimir uma marca distintiva nos sujeitos. Mesmo quando a linguagem verbal não diz, ou até quando nega, as imagens veiculadas por este tipo de texto promovem, em sua maioria, a subordinação social e sexual da mulher. Em muitas propagandas veiculadas na sociedade, ainda se mantém uma visão estereotipada sobre a mulher, representada a partir de seus atributos físicos em primeiro lugar. O corpo feminino é visto preferencialmente desnudo, vendendo os mais variados produtos (bebidas alcoólicas, carros, produtos de emagrecimento e bem-estar etc.). Os anúncios publicitários, muitas vezes, apresentam as mulheres de modo estereotipado e 
distorcido através de imagens sexistas. Elas são sempre belas e têm corpos perfeitos, de acordo com os padrões de beleza sociais.

A associação entre a produção de imagens corporais pela mídia e a percepção dos corpos/construção de auto-imagem, por parte dos indivíduos, é imediata. Nenhuma outra sociedade na história produziu e disseminou tal volume de imagens do corpo humano através da mídia como a nossa. A atual busca de cultuar e modelar o próprio corpo é marcada por diversas técnicas corporais legitimadas na nossa sociedade e inserida em um movimento social mais amplo, que vem se acirrando no contexto da modernidade, dentro de uma lógica consumista (GREGOLIN, 2007b, p. 20).

A sociedade do consumo e do espetáculo, cujas imagens de mulheres belas, felizes e bem-sucedidas estão sempre "em cena", produz um cenário perfeito para que o sujeito feminino deseje transformar seu corpo para corresponder ao desejo cultural e assim garantir um lugar no palco desse espetáculo e atrair o olhar do outro.

Em nenhuma outra época, o corpo magro possuiu um sentido de corpo ideal e esteve tão em evidência como na atualidade (VIGARELLO, 2006). Está na moda o corpo magro, nu ou vestido, exposto em diversas revistas femininas e masculinas, nas capas de revistas, em matérias jornalísticas, no discurso publicitário. Na sociedade contemporânea, vivemos a época da "lipofobia", isto é, uma época que tem obsessão pela magreza e rejeição doentia à obesidade. A Figura 1 mostra uma propaganda que exemplifica essa valorização da magreza na sociedade.

O corpo magro se transformou em sonho de consumo de milhares de mulheres, nem que para isto elas tenham que se submeterem a intervenções cirúrgicas (lipoaspiração, por exemplo), dietas de todos os tipos ou exercícios físicos rigorosos. Considerando os múltiplos olhares sobre a mulher que a pluralidade do discurso publicitário faz emergir na sociedade, lançamos aqui nosso olhar sobre três anúncios publicitários.

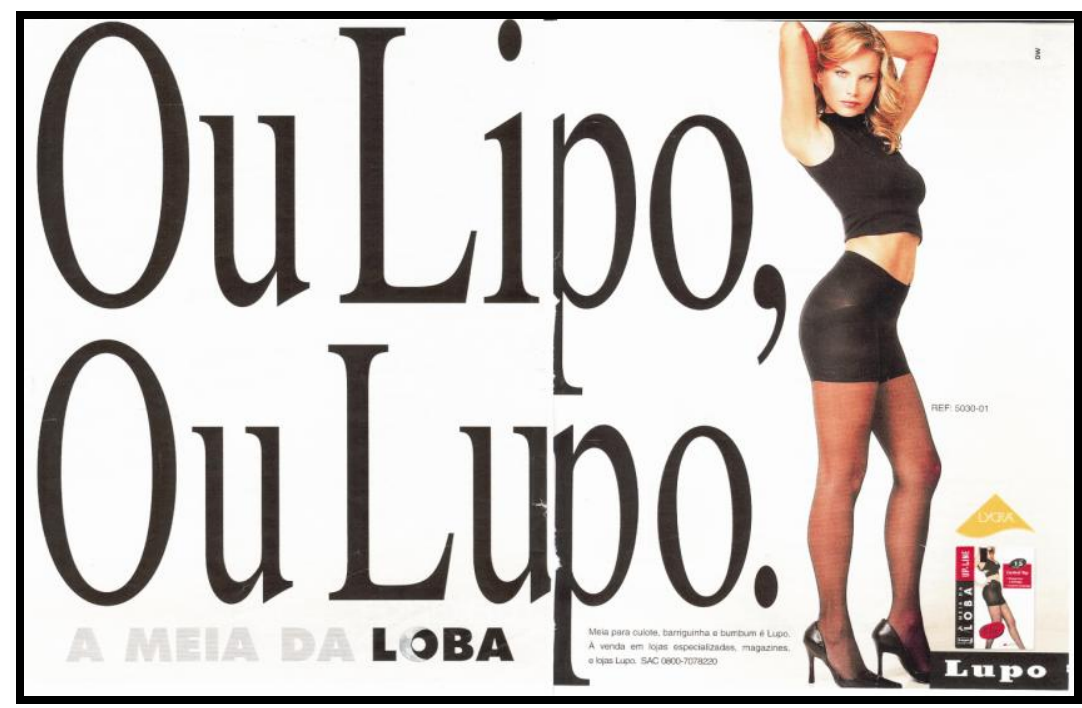

Figura 1: Ou Lipo, ou Lupo

Fonte: <http://site.lupo.com.br/publicidade/> Acesso em: 20 mar. 2014.

Na Figura 1, o enunciado "ou lipo, ou Lupo" está diretamente ligado à ideia de um corpo escultural, magro e belo. A mulher dispõe de duas opções: ou faz uma 
lipoaspiração ou usa produtos Lupo para manter-se esbelta. O produto anunciado ajusta-se sensualmente ao corpo, modelando a barriga e os quadris, o que leva à conclusão de que os produtos Lupo fazem no corpo feminino, em poucos segundos, o que uma mulher levaria meses para conseguir em uma academia. Assim, o corpo, matéria-prima vendida pelo discurso publicitário, não só recebe sentido pelo discurso, mas é inteiramente constituído por ele. Resultado de práticas individualizadas de embelezamento e cuidados de si, o corpo é assujeitado pelo discurso da beleza perene. Os sujeitos sociais buscam adequar o corpo às normas científicas da saúde, longevidade, equilíbrio, para atender às rígidas exigências da cultura do espetáculo da mídia (GREGOLIN, 2003).

$\mathrm{O}$ culto à magreza, inserido dentro de um rígido padrão de beleza, gera práticas disciplinares sustentadas pela construção que associa a magreza à saúde e ao esteticamente belo. Segundo Foucault (2008a, p. 148), quanto maior a atenção sobre o corpo, maior é o controle sobre ele. Por exemplo, o simples ato disciplinar de escovar os dentes diariamente é justificado pelo discurso médico-científico que objetiva manter pacífica a obrigatoriedade deste ato corriqueiro. Segundo o filósofo francês, a maior astúcia da sociedade disciplinar é tornar o poder controlador em algo prazeroso.

Ao discutir a produção de identidades na mídia, Gregolin (2007a) afirma que

o trabalho discursivo de identidades desenvolvido pela mídia cumpre funções sociais básicas [...]. Essas funções são asseguradas pela ampla oferta de modelos difundidos e impostos socialmente por processos de imitação e formas ritualizadas. Esses modelos de identidades são socialmente úteis, pois estabelecem paradigmas, estereótipos, maneiras de agir e pensar que simbolicamente inserem o sujeito na 'comunidade imaginada'. A sofisticação produz uma verdadeira saturação identitária através da circulação incessante de imagens que têm o objetivo de generalizar modelos. A profusão dessas imagens age como um dispositivo de etiquetagem e de disciplinamento do corpo social (GREGOLIN, 2007a, p. 50).

A superexposição de modelos corporais nos meios midiáticos contribui para a divulgação de uma ótica corpórea estereotipada e determinada pelas relações de consumo. A mídia contemporânea expõe somente corpos que se encaixam em um padrão estético perfeito e "aceitável", mediado pelos interesses da indústria de consumo.

Na sociedade do espetáculo (GREGOLIN, 2003), há uma supervalorização da aparência física do corpo, fruto de sua excessiva exposição na mídia. Constantemente são apresentados modelos para uma estetização do corpo feminino através de uma exacerbação de imagens, o que ocorre principalmente na publicidade. Mercados como os da moda, da publicidade e da estética são hoje os principais mantenedores da estetização do corpo feminino. Através da circulação incessante de imagens, como as que são apresentadas nas Figuras 2 e 3, estabelece-se um padrão de beleza por meio de uma modelagem perfeita do corpo feminino, construída a partir do consumo de produtos diet. Tais anúncios fazem parte de uma rede de mecanismos sociais que apregoam e controlam a modelagem dos corpos. 
A Figura 2 mostra uma modelo que exibe um corpo magérrimo, possível de ser percebido através de uma cortina entreaberta. Isso sugere que a ingestão de produtos diet (refrigerantes, adoçantes e sobremesas) no cardápio possibilita atingir uma minimalidade do corpo que, conforme Gregolin (2007a, p. 52), é "uma espécie de grau zero do corpo [...] apresentada como ideal, um corpo-mínimo associado, em inúmeros enunciados, à saúde e à beleza e oferecido como objetivo a ser alcançado, como meta almejada estética e eticamente" (grifos da autora). Este corpo mínimo é espetacularizado no discurso midiático, dentro do lema "quanto menos, mais evidente". A propaganda da Figura 2 apresenta o corpo magérrimo, esguio, retilíneo, que se torna evidente em uma estreita abertura de uma cortina.

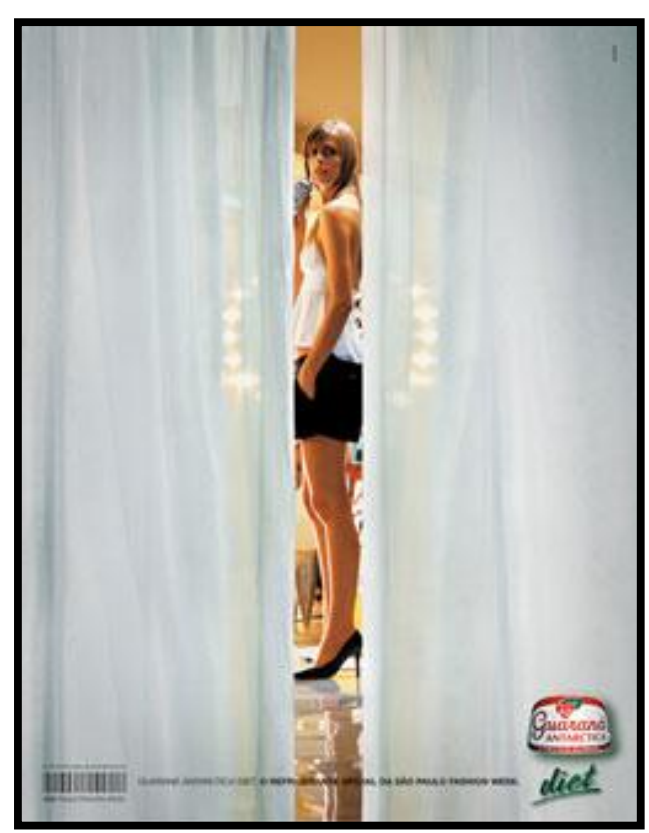

Figura 2: Guaraná Antarctica Diet -Patrocinador oficial da São Paulo Fashion Week 2006 Fonte: <http://contem1criativo.blogspot.com/2005_01_01_archive.html> Acesso em: 20 mar. 2014

Se atentarmos para as diferentes maneiras como o corpo é tratado em diversos campos sociais, manifestadas nas práticas discursivas, é possível vislumbrarmos quer seja na medicina, na publicidade, na moda, na indústria de produtos light/diet etc., um discurso sobre o corpo que soa uníssono, e que tem como pressuposto a importância da saúde revelada no corpo magro e na valorização exacerbada dos atributos físicos, caracterizados por formas magras e bem definidas. Para Foucault (20008b), essas práticas discursivas são práticas sociais que instituem tanto o objeto de que falam - o discurso, como o comportamento aprendido pelo visível - o não-discursivo, e constituem o se poderia chamar a tecnologia política do corpo.

O corpo feminino é visto como manifestação discursiva, apelando para o dito e o não-dito na publicidade. O estereótipo clássico globalizado da mulher atraente, difundido pela mídia, é o da mulher com corpo escultural, sem excesso de peso, o modelo da "mulher violão", com seios fartos, cintura fina e quadris largos. Os padrões de beleza atuais são rígidos e defendem o estereótipo da mulher magra e jovem. 
A modelo que aparece na Figura 3 tem cintura acentuada, quadris largos e empinados, seios firmes, todos esses atributos físicos ressaltados por um vestido vermelho transparente que enfatiza a sensualidade do corpo da modelo. A partir dessa imagem se estabelece o desejo de consumir o produto anunciado, na busca de conseguir um corpo como o que está também anunciado. Dessa forma, o corpo ocupa um lugar de destaque que se articula fortemente com o consumo: o corpo-mercadoria.

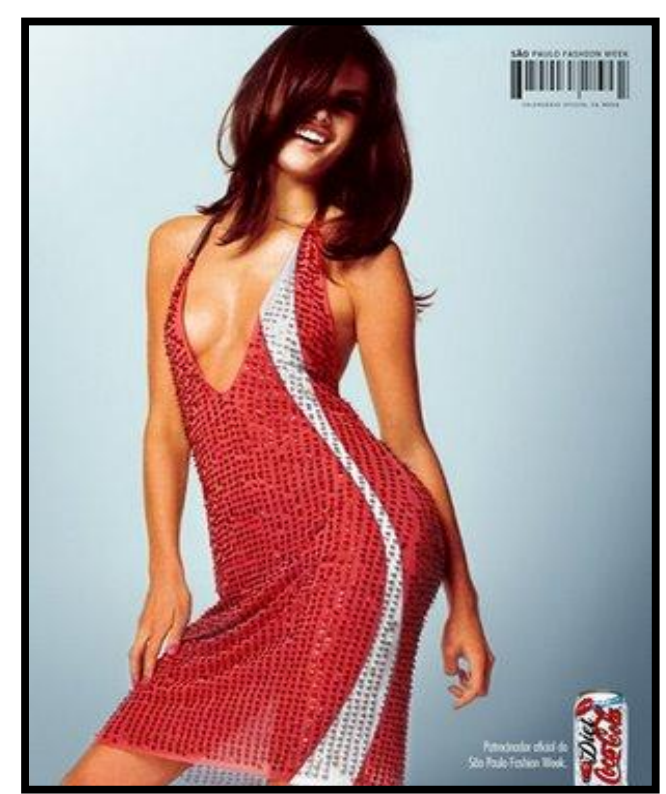

Figura 3: Coca-Cola Diet - Patrocinador oficial da São Paulo Fashion Week 2008 Fonte: <www.humorintenso.com.br/?paged=38> Acesso em: 20 mar. 2014.

Há uma espécie de adestramento do corpo através da vigilância exercida pelo discurso publicitário que propaga imagens que agem como dispositivos de disciplinamento do corpo social desaparecido como entidade biológica, tornando-se um produto construído de maneira maleável e instável. Ele é a ferramenta, o instrumento de trabalho das modelos nas propagandas que apregoam o corpo como mercadoria. $\mathrm{O}$ corpo escultural discursivizado na publicidade convoca à ação de consumir o produto anunciado. Prometendo realizar sonhos, a publicidade pretende que o consumidor se veja refletido nas imagens veiculadas, estimulando sua identificação com o corpo divulgado.

As propagandas apresentadas nas Figuras 1, 2 e 3 agem como dispositivos de disciplinamento e têm circulação incessante na mídia com o objetivo de generalizar modelos corporais. Todas reiteram insistentemente a positividade do corpo mínimo.

Esculpir a silhueta começa a se tornar um dever, a beleza é submetida a um trabalho de pensamento que busca afirmar a confiança em si. Segundo Vigarello (2006, p. 219), "o corpo é uma argila que se molda à vontade da cultura física e aos cuidados da beleza". No imediatismo de uma sociedade que cultua a beleza e que se rende aos fenômenos midiáticos, aumenta, cada vez mais, a necessidade de os indivíduos se exporem em conformidade com os padrões de uma beleza perfeita. O excesso de 
exposição de belas modelos, tornando-as celebridades, ditou um novo padrão de beleza para as mulheres. O mito da beleza nunca foi tão explorado antes como nos dias atuais.

Em entrevista à Agência Fiocruz de Notícias², a historiadora Ana Paula Vosne Martins discorreu sobre a construção do corpo feminino. Para ela, a "ditadura" da estética e a imposição por parte dos meios de comunicação da mulher ideal podem ser consideradas ameaças à saúde física e mental da mulher. Na visão da pesquisadora, a corpolatria e o ideal de beleza não atingem igualmente as mulheres: variam conforme a região, a classe social, a educação, o acesso às informações, entre outros fatores. Para a historiadora, as adolescentes são as mais atingidas pelos rígidos modelos impostos pela moda, pela publicidade, cinema e televisão. Ela afirma que:

\begin{abstract}
Como a magreza e a juventude são, hoje, sinônimos de felicidade, sucesso e ascensão social - há várias top models brasileiras para citar como exemplo as meninas começam muito cedo a se preocupar com sua imagem, com o peso, com cabelos e pele. Não acho que elas devam se despreocupar com a aparência, mas a obsessão pode, sim, levar a comportamentos cada vez mais individualistas e desenvolver síndromes como a bulimia e a anorexia, levando, em casos extremos, à morte (MARTINS, 2005, p. 03).
\end{abstract}

A mídia participa da construção social do corpo. Seria ingênuo de nossa parte presumir uma neutralidade no discurso midiático, até porque, como reflete Foucault (2000, p. 9), um discurso está longe de ser transparente ou neutro. Nesse sentido, consideramos que é preciso dar relevância aos discursos produzidos e reproduzidos no espetáculo da mídia, pois a relação que o sujeito constroi com seu corpo é atravessada por estes discursos.

\title{
5) Comentários finais
}

A tarefa de investigar a supremacia do corpo na sociedade contemporânea é inesgotável. Essa problemática requer um aprofundamento em várias perspectivas: científica, sociológica, antropológica, histórica etc. Neste artigo, foram apontadas, de forma geral e sucinta, algumas reflexões que consideramos relevantes em relação ao presente fenômeno do culto ao corpo e do imperativo da magreza que o acompanha. A tirania da estética e a construção e imposição do corpo ideal veiculadas no discurso publicitário podem ser consideradas graves ameaças à saúde da mulher atual.

A busca pela metamorfose corporal traduz um investimento narcísico que reflete a relação indivíduo x sociedade. $O$ corpo é o suporte da transformação do sujeito desejante, nele são depositadas as expectativas de transformação do sujeito em sua relação com o mundo, buscando visibilidade por meio das transformações corporais, adicionando ou, ao contrário, extraindo ou modificando o que não deve ser visto. Este desejo narcísico é fruto de idealizações que nem sempre correspondem à realidade e, em geral, correspondem a desejos e projeções de sujeitos que não conhecem a verdadeira

\footnotetext{
${ }^{2}$ Disponível em: <http://www.fiocruz.br/ ccs/arquivosite/entrevista/ana.martins.htm〉. Acesso em: 15 jun. 2014.
} 
dimensão desta necessidade de transformação, suas causas reais, nem as consequências adversas que podem vir a acontecer.

A constante valorização do corpo "perfeito" induz a mulher a não aceitar sua própria imagem, modificando-a de acordo com os ideais de beleza vigente. O corpo midiático torna-se descorporizado, na medida em que o que "exprime" é justamente um corpo "perfeito", belo, jovem, leve, quase sem "peso", livre de rugas, isto é, um corpo que parece ignorar suas próprias marcas constituintes, um corpo sem história. $\mathrm{O}$ corpo transformado em objeto passa a ser construído, formatado, reparado e esculpido. $\mathrm{Na}$ cultura contemporânea, esse objeto ultrapassa os limites biológicos, é normatizado e homogeneizado, estruturado por medidas corporais cada vez mais utópicas.

A mídia é uma vitrine de físicos esbeltos, onde quem construir a melhor imagem terá seu corpo aceito e comprado. Existe um excesso de imagens que insistem em dizer o tempo todo, de forma exagerada, porém sedutora, que a mulher deve ser bela, e isso significa ser magra, ser jovem, cada vez mais jovem, ter um biótipo ideal dentro de um padrão estético rigoroso.

Mulheres consumistas, que gastam tempo, dinheiro e energia para se enquadrar no rígido modelo corporal da indústria do fitness, são versões modernizadas pela tecnologia da mulher-corpo, criada pela ciência e medicina da contemporaneidade. Não representam ameaça para os valores sociais estabelecidos e dificilmente podem trazer alguma contribuição para qualquer processo de mudança ou de questionamento da ordem social. Como já dizia Foucault (2008a), são corpos dóceis, submissos, facilmente manipulados, disciplinados e governados.

\section{6) Referências}

BAUMAN, Zygmunt. Modernidade líquida. Rio de Janeiro: Jorge Zahar, 2001.

CARVALHO, Nelly. Publicidade: a linguagem da sedução. São Paulo: Ática, 2000.

DEBORD, Guy. Comentários sobre a sociedade do espetáculo. In: A sociedade do espetáculo. Tradução de Estela Abreu. Rio de Janeiro: Contraponto, 1997, p. 165237.

FOUCAULT, Michel. Vigiar e punir: nascimento da prisão. 36. ed. Tradução de Raquel Ramalhete. Petrópolis, RJ: Vozes, 2009. Graal, 2008a.

Microfísica do poder. Tradução de Roberto Machado. 25. ed. Rio de Janeiro:

A Arqueologia do Saber. Tradução de Luiz Felipe Baeta Neves. 7. ed. Rio de Janeiro: Forense Universitária, 2008b.

História da Sexualidade 3. (O cuidado de si) Tradução de Maria Thereza da Costa Albuquerque. Rio de Janeiro: Graal, 2007. 
A ordem do discurso. 12 ed. Tradução Laura Fraga de Almeida Sampaio. São Paulo: Edições Loyola, 2000.

GREGOLIN, Maria do Rosário (Org.) Discurso e mídia - a cultura do espetáculo. São Carlos, SP: Claraluz, 2003.

Discurso, História e a Produção de Identidades na Mídia. In: POSSENTI, Sírio; FONSECA-SILVA, Maria da C. (Orgs.) Mídia e Rede de Memória. Vitória da Conquista, BA: Edições UESB, 2007a, p. 39-60.

Análise do Discurso e mídia: a (re)produção de identidades. Dossiê. Comunicação, Mídia e Consumo. São Paulo, vol. 4, n 11, Nov. 2007b, p. 11-25.

HALL, Stuart. A identidade cultural na pós-modernidade. Tradução de Tomaz Tadeu da Silva Guaracira Lopes Louro. 11ed. Rio de Janeiro: DP\&A, 2006.

MARTINS, Ana Paula V. Entrevista à Agência Fiocruz de Notícias. 2005. Disponível em: <http://www.fiocruz.br/ ccs/arquivosite/entrevista/ana.martins.htm> Acesso em: 15 jun. 2014.

SANTAELLA, Lucia. Corpo e comunicação - sintoma da cultura. São Paulo: Paulus, 2004.

VESTERGAARD, T \& SCHRODER, K. A linguagem da propaganda. 3. ed. São Paulo: Martins Fontes, 2000.

VIGARELLO, Georges. A história da beleza: o corpo e arte de se embelezar, do renascimento aos dias de hoje. Tradução Léo Schlafman. Rio de Janeiro: Ediouro, 2006. 